\title{
Rendimentos de carcaça, composição tecidual e musculosidade da perna de cordeiros alimentados com silagem de milho ou cana-de-açúcar em dois níveis de concentrado
}

\author{
[Carcass yield, tissue composition, and leg muscularity of lambs fed corn silage or sugar \\ cane in two levels of concentrate] \\ G.M.B. Moreno ${ }^{1}$, A.G.S. Sobrinho ${ }^{2}$, A.G. Leão ${ }^{3}$, C.M.B. Loureiro $^{1}$, H.L. Perez ${ }^{4}$ \\ ${ }^{1}$ Alunos de pós-graduação - FCAV- UNESP - Jaboticabal, SP \\ ${ }^{2}$ Faculdade de Ciências Agrárias e Veterinárias - UNESP - Jaboticabal, SP \\ ${ }^{3}$ Aluno de pós-graduação - UFBA - Salvador, BA \\ ${ }^{4}$ Zootecnista - Bolsista do CNPq
}

\begin{abstract}
RESUMO
Avaliou-se o efeito da relação volumoso:concentrado e do tipo de volumoso nos rendimentos de carcaça e dos cortes comerciais, e sobre a composição dos tecidos e musculosidade da perna de 32 cordeiros Ile de France, terminados em confinamento, alimentados com silagem de milho ou cana-de-açúcar, em duas relações volumoso:concentrado: de 60:40 ou 40:60. Os cordeiros foram abatidos aos 32kg de peso corporal; calcularam-se o peso e o rendimento da carcaça quente (PCQ e RCQ). Após 24 horas de refrigeração, obtiveram-se o peso e o rendimento da carcaça fria (PCF e RCF), o rendimento verdadeiro e as perdas por resfriamento. As carcaças foram divididas em cinco cortes comerciais, paleta, lombo, perna, costelas e pescoço, e a perna foi dissecada em músculo, osso e gordura, calculando-se as relações músculo:osso e músculo:gordura, além do índice de musculosidade da perna. Os cordeiros alimentados com silagem de milho apresentaram maiores PCQ $(16,05 \mathrm{~kg})$, PCF $(15,61 \mathrm{~kg})$, RCQ $(50,4 \%)$ e RCF $(49,0 \%)$. O rendimento de lombo foi menor nos cordeiros alimentados com cana-de-açúcar $(9,1 \%)$. A cana-de-açúcar e a silagem de milho nas duas relações volumoso:concentrado estudadas não afetaram as proporções de osso, músculo e gordura e musculosidade da perna, e podem constituir a dieta desses animais sem diminuir as proporções desses tecidos, responsáveis pela qualidade da carne.
\end{abstract}

Palavras-chave: ovino, confinamento, carcaça, cortes comerciais, relação volumoso:concentrado

\begin{abstract}
The effects of roughage:concentrate ratio and type of roughage were evaluated on the carcass yield and commercial cuts, and tissue composition and leg muscularity of 32 Ile de France lambs finished in feedlot and fed corn silage or sugar cane in two roughage:concentrate ratios: 60:40 or 40:60. The lambs were slaughtered with $32 \mathrm{~kg}$ of body weight and the weight and yield of hot carcass (WHC and YHC) were determined. After refrigerated for $24 \mathrm{~h}$ in cold camera, the weight and yield of cold carcass (WCC and $Y C C)$, real yield, and weight loss for cooling were obtained. The carcass was divided in five commercial cuts (shoulder, loin, leg, ribs, and neck), and the leg was dissected on muscle, bone, and fat, and the relations muscle:bone and muscle:fat and also the leg muscularity index were calculated. The lambs fed corn silage showed higher WHC (16.05kg), WCC (15.61 kg), YHC (50.42\%), and YCC (49.03\%). The loin yield was lower in lambs fed sugar cane $(9.11 \%)$. The sugar cane and corn silage in this two roughage:concentrate ratios did not affect the proportions of muscle, bone, and fat, and leg muscularity. Therefore, they can be used in diets for animals without reducing the proportions of these tissues, that are related to meat quality.
\end{abstract}

Keywords: sheep, feedlot, carcass, commercial cuts, roughage:concentrate ratio

Recebido em 12 de janeiro de 2009

Aceito em 30 de abril de 2010

E-mail: greicymitzimoreno@yahoo.com.br

Apoio financeiro: FAPESP 


\section{INTRODUÇÃO}

A produção de carne de cordeiro é uma atividade com grandes perspectivas no Brasil, considerando o potencial do mercado consumidor e a possibilidade de se produzir carne de qualidade em pequenas áreas de terra. Entretanto, a comercialização da carcaça e da carne depende, além do peso, da forma como é apresentada ao consumidor e, por isso, a aparência do produto constitui fator importante para sua aceitação no mercado (Santos e Pérez, 2000). Segundo Brochier e Carvalho (2009), apesar de a carne ovina ser uma fonte de proteína de alto valor biológico, só será competitiva frente às carnes de outras espécies se o produtor disponibilizar no mercado carne de animais jovens, criados de maneira adequada para obtenção de carcaças de primeira qualidade.

Para ser eficiente neste mercado cada vez mais competitivo, é necessário melhorar os sistemas de produção, fazendo com que a carne ovina apresente parâmetros de qualidade desejáveis, tanto quantitativos como qualitativos (Santos, 2002). Assim, a utilização de métodos que avaliem as carcaças e que permitam predizer sua qualidade e composição em músculo, osso e gordura é fundamental. A avaliação das características quantitativas do animal vivo e da carcaça pode, conjuntamente, predizer o rendimento e a composição dos cortes comerciais.

O método mais preciso para determinar a composição dos tecidos da carcaça é a dissecação, que consiste na separação dos músculos, ossos, gorduras e outros componentes. Contudo, a dissecação de toda a carcaça ou da meia carcaça apenas se justifica em casos especiais, por ser lenta, trabalhosa e onerosa, sendo mais comum a dissecação dos principais cortes comerciais, como paleta ou perna, por apresentarem alto coeficiente de correlação com a composição total da carcaça e constituírem, juntos, mais de $50 \%$ da carcaça ovina (Oliveira et al., 1998; Cezar e Sousa, 2007).

De acordo com Silva Sobrinho (2001), cordeiros de raças especializadas para carne apresentam rendimento de carcaça que varia de 40 a $50 \%$, o qual é influenciado por fatores intrínsecos, extrínsecos e da carcaça propriamente dita. A raça Ile de France apresenta elevado ganho de peso diário e produz carcaças compactas e de qualidade, em que os cortes nobres (perna, lombo e paleta) representam cerca de $55 \%$ do peso total da carcaça, o que lhe confere maior aproveitamento.

A proporção de músculo na carcaça também pode ser estimada pelo índice de musculosidade da perna, que considera a profundidade média de um grupo de músculos que circundam o fêmur em relação ao comprimento desse osso (Purchas et al., 1991). O índice de musculosidade da perna representa bem a relação músculo:osso, sendo tanto maior quanto maior for a quantidade de carne nas carcaças.

Os objetivos deste trabalho foram avaliar o rendimento de carcaça, a composição dos tecidos e o índice de musculosidade da perna de cordeiros Ile de France terminados em confinamento e alimentados com silagem de milho ou cana-de-açúcar em dois níveis de concentrado.

\section{MATERIAL E MÉTODOS}

Foram utilizados 32 cordeiros Ile de France, machos não castrados, com peso inicial médio de $15 \mathrm{~kg}$ e distribuídos em quatro tratamentos, constituídos por dietas com duas relações volumoso:concentrado, sendo: $60 \%$ de silagem de milho (SM) $+40 \%$ de concentrado (C) (60\%SM:40\%C); 60\% de cana-de-açúcar (CA) + $40 \%$ de concentrado $(60 \% \mathrm{CA}: 40 \% \mathrm{C}) ; 40 \%$ de silagem de milho $+60 \%$ de concentrado (40\%SM:60\%C) e 40\% de cana-de-açúcar + $60 \%$ de concentrado (40\%CA:60\%C).

A cana-de-açúcar utilizada foi a variedade forrageira IAC 86-2480, proveniente do primeiro corte, colhida manualmente em dias alternados e picada imediatamente antes do fornecimento aos animais. As dietas foram calculadas de acordo com as exigências preconizadas pelo NRC (Nutrient..., 1985) para cordeiros desmamados com ganhos de peso estimados em $300 \mathrm{~g} /$ dia. O concentrado foi composto por grão de milho triturado, farelo de soja, ureia, sal comum, calcário calcítico, fosfato bicálcico e suplemento vitamínico e mineral, constituindo dietas isoproteicas e isoenergéticas. Na Tab. 1, podem ser visualizadas as composições percentual e químico-bromatológica das dietas, expressas na matéria seca. 
Tabela 1. Composição dos ingredientes, análise químico-bromatológica e energia metabolizável das dietas experimentais (expressas na matéria seca) usadas para cordeiros

\begin{tabular}{lcccc}
\hline Composição (\% da MS) & $60 \%$ SM:40\%C & $60 \%$ CA:40\%C & $40 \%$ SM:60\%C & $40 \%$ CA:60\%C \\
\hline Silagem de milho & 60,00 & - & 40,00 & - \\
Cana-de-açúcar & - & 60,00 & - & 40,00 \\
Ureia & 1,00 & 1,00 & 0,20 & 1,00 \\
Milho moído & 19,20 & 9,55 & 34,10 & 32,30 \\
Farelo de soja & 17,40 & 27,65 & 23,30 & 24,30 \\
Sal iodado & 0,30 & 0,20 & 0,30 & 0,30 \\
Calcário calcítico & 1,30 & 0,60 & 1,30 & 1,20 \\
Fosfato bicálcico & 0,30 & 0,50 & 0,30 & 0,40 \\
Núcleo mineral & 0,50 & 0,50 & 0,50 & 0,50 \\
Químico-bromatológica (na MS) & & & & \\
Material seca (\%) & 53,71 & 52,37 & 65,83 & 64,59 \\
Proteína bruta (\%) & 18,61 & 19,61 & 20,33 & 20,35 \\
Matéria mineral (\%) & 5,67 & 4,52 & 5,81 & 5,26 \\
Fibra em detergente neutro (\%) & 32,46 & 26,15 & 24,13 & 21,81 \\
Fibra em detergente ácido (\%) & 15,22 & 14,62 & 11,73 & 10,96 \\
Lignina (\%) & 2,16 & 2,76 & 2,36 & 2,02 \\
Extrato etéreo (\%) & 3,09 & 1,15 & 3,15 & 2,00 \\
Matéria orgânica (\%) & 94,33 & 95,48 & 94,19 & 94,74 \\
Carboidratos totais (\%) & 72,63 & 74,73 & 70,70 & 72,39 \\
Carboidratos fibrosos (\%) & 40,16 & 48,58 & 46,58 & 50,58 \\
Energia metabolizável (Mcal/kg) & 3,91 & 3,81 & 3,94 & 3,83 \\
Cálcio (\%) & 0,74 & 0,65 & 0,75 & 0,81 \\
Fósforo (\%) & 0,38 & 0,36 & 0,41 & 0,36 \\
\hline Tro & & &
\end{tabular}

Tratamento: $60 \% \mathrm{SM}: 40 \% \mathrm{C}=60 \%$ silagem de milho $+40 \%$ concentrado; $60 \% \mathrm{CA}: 40 \% \mathrm{C}=60 \%$ cana-de-açúcar + $40 \%$ concentrado; $40 \% \mathrm{SM}: 60 \% \mathrm{C}=40 \%$ silagem de milho $+60 \%$ concentrado $; 40 \% \mathrm{CA}: 60 \% \mathrm{C}=40 \%$ cana-deaçúcar $+60 \%$ concentrado. MS = matéria seca.

${ }^{1}$ Núcleo mineral: Zn 1600mg; Cu 300mg; Mn 1500mg; Fe 1100mg; Co 10mg; I 27mg; Se 22mg.

Os cordeiros foram alojados individualmente em baias de piso ripado e suspenso, com aproximadamente $1,0 \mathrm{~m}^{2}$, equipadas com comedouro e bebedouro e dispostas em área coberta. A alimentação foi fornecida às $7 \mathrm{~h}$ e às $17 \mathrm{~h}$, com controle diário, que permitia sobras de $20 \%$, e as pesagens realizadas semanalmente.

Ao atingirem $32 \mathrm{~kg}$ de peso corporal, os animais foram pesados e submetidos a jejum de dieta sólida por 16 horas. Previamente ao abate, os animais foram novamente pesados para obtenção do peso corporal ao abate (PCA), insensibilizados por eletronarcose $\mathrm{e}$ posteriormente foram abatidos por secção das veias jugulares e das artérias carótidas. Em seguida, o trato gastrintestinal foi retirado $\mathrm{e}$ esvaziado para obtenção do peso corporal vazio (PCV = PCA - conteúdo gastrintestinal), visando determinar o rendimento verdadeiro ou biológico (RV), obtido pela relação entre o peso da carcaça quente e o peso corporal vazio (Sañudo e Sierra, 1986).

Após a evisceração, as carcaças foram pesadas peso de carcaça quente (PCQ) - para determinação do rendimento da carcaça quente $\left(\mathrm{RCQ}=\mathrm{PCQ} / \mathrm{PCA}^{*} 100\right)$ e transferidas para câmara frigorífica a $4^{\circ} \mathrm{C}$ por 24 horas, penduradas pelos tendões do gastrocnêmio. Ao final desse período, as carcaças frias foram pesadas - peso de carcaça fria $(\mathrm{PCF})$-, para calcular o rendimento de carcaça fria $(\mathrm{RCF}=$ PCF/PCA*100) e a perda de peso por resfriamento $(\mathrm{PR}=(\mathrm{PCQ}-\mathrm{PCF} / \mathrm{PCQ}) * 100)$.

Após a pesagem, as carcaças foram divididas longitudinalmente e seccionadas em cinco 
regiões anatômicas: pescoço, paleta, costelas, lombo e perna, segundo metodologia adaptada de Silva Sobrinho (1999). Os cortes comerciais foram pesados separadamente, e, em seguida, foram calculadas as porcentagens de cada corte em relação à meia carcaça esquerda. Após a obtenção dos cortes comerciais, as pernas esquerdas foram identificadas, armazenadas em sacos plásticos e congeladas em freezer a $-18^{\circ} \mathrm{C}$, para facilitar as atividades posteriores de dissecação. Após o descongelamento em geladeira a $10^{\circ} \mathrm{C}$, por 24 horas, dentro dos sacos plásticos, foram retiradas e pesadas individualmente.

Antes da dissecação, retiraram-se das pernas todo o tecido extra, a gordura associada, os canais de gordura, outros tecidos moles mediais ao osso pélvico e as vértebras caudais, excetuando-se as duas primeiras. Removeu-se a extremidade distal do osso da tíbia, deixando o tendão do gastrocnêmio solto, e, em seguida, foi realizada a toalete abaixo das vértebras sacras, retirando-se a musculatura da prega do flanco, a gordura do canal pélvico e a articulação tarsometatarsiana (Pinheiro, 2006).

As pernas limpas foram, então, pesadas, e iniciou-se a dissecação com o auxílio de bisturi e faca, para determinação da composição dos tecidos em gorduras subcutânea - gordura externa, localizada diretamente abaixo da pele e intermuscular - gordura abaixo da fáscia profunda, associada aos músculos-, músculos total de músculos dissecados após a remoção completa de todas as gorduras subcutânea e intermuscular aderidas - e ossos - ossos dissecados após a remoção completa de todos os músculos e gorduras subcutânea e intermuscular aderidas -, que foram pesados, individualmente, para serem expressos, em porcentagem, em relação ao peso da perna, conforme citado por McCutcheon et al. (1993).

Os músculos que recobrem o fêmur, Biceps femoris Semitendinosus, Adductor, Semimembranosus e Quadriceps femoris, foram retirados e pesados separadamente para determinação do índice de musculosidade da perna. Os outros, que não envolviam diretamente o fêmur, foram retirados e pesados juntos para determinar a porcentagem de músculo total. Os ossos foram pesados em conjunto e, posteriormente, o fêmur foi pesado individualmente e seu comprimento medido com auxílio de fita métrica (Fig. 1). A metodologia utilizada para dissecação das pernas foi a proposta por Brown e Willians (1979).

$O$ índice de musculosidade da perna foi calculado segundo Purchas et al. (1991): $I M=\frac{\sqrt{P M 5 / C F}}{C F}$, em que IM = índice de musculosidade; PM 5 = peso (g) dos cinco músculos que recobrem o fêmur (Biceps femoris, Semitendinosus, Adductor, Semimembranosus e Quadriceps femoris) e $\mathrm{CF}=$ comprimento $(\mathrm{cm})$ do fêmur.



Figura 1. Representação da medição do comprimento do fêmur. Adaptado de Butterfield (1988).

$\mathrm{O}$ delineamento experimental foi o inteiramente ao acaso, em esquema fatorial $2 \times 2$ (dois volumosos duas relações volumoso:concentrado). Os dados foram submetidos à análise de variância pelo procedimento GLM do pacote estatístico
SAS/1996 a 5\% de significância. Quando detectadas diferenças significativas entre os tratamentos para as diferentes variáveis em estudo, elas foram comparadas pelo teste Tukey, no mesmo nível de significância. 


\section{RESULTADOS E DISCUSSÃO}

As médias e os coeficientes de variação das características quantitativas da carcaça são apresentadas na Tab. 2. Houve interação $(\mathrm{P}<0,05)$ da relação volumoso:concentrado e tipo de volumoso apenas para PCA.

Houve influência $(\mathrm{P}<0,05)$ do tipo de volumoso para pesos do corpo vazio, de carcaça quente e de carcaça fria, e para rendimentos de carcaça quente e fria. Os animais alimentados com silagem de milho apresentaram maiores valores. Segundo Yamamoto (2006), o peso da carcaça é influenciado pela velocidade de crescimento, pela idade ao abate, pelo manejo nutricional e é um importante fator na estimativa de rendimento.
Zundt et al. (2003), ao avaliarem as características de carcaça de cordeiros machos e fêmeas cruzados (Texel $\mathrm{x}$ Bergamácia $\mathrm{x}$ Corriedale), alimentados com níveis crescentes de proteína na dieta e abatidos aos $40 \mathrm{~kg}$ de peso corporal, não observaram efeito de sexo e do nível proteico para pesos de carcaça quente e fria, com valores médios de 18,6 e 17,9kg, respectivamente, superiores aos encontrados neste estudo. Segundo Silva e Pires (2000), maior rendimento de carcaça ovina é encontrado em animais mais jovens, devido ao aumento do trato gastrintestinal com o avançar da idade, que diminui o rendimento de carcaça. Vale ressaltar que a valorização da carcaça ovina depende da relação entre peso corporal e idade, em que se busca maior peso à menor idade.

Tabela 2. Peso corporal (PC), pesos corporal ao abate (PCA), do corpo vazio (PCV), da carcaça quente (PCQ) e fria (PCF), perdas de peso por resfriamento (PPR), e rendimentos de carcaça quente (RCQ), fria (RCF) e verdadeiro (RV) da carcaça de cordeiros alimentados com silagem de milho ou cana-de-açúcar em dois níveis de concentrado

\begin{tabular}{|c|c|c|c|c|c|c|}
\hline \multirow{2}{*}{ Variável } & \multicolumn{2}{|c|}{$\begin{array}{c}\text { Relação } \\
\text { volumoso:concentrado }\end{array}$} & \multicolumn{2}{|c|}{ Volumoso } & \multirow{2}{*}{ Interação } & \multirow{2}{*}{$\begin{array}{l}\mathrm{CV} \\
(\%)\end{array}$} \\
\hline & $40: 60$ & $60: 40$ & $\begin{array}{l}\text { Cana-de- } \\
\text { açúcar }\end{array}$ & $\begin{array}{l}\text { Silagem de } \\
\text { milho }\end{array}$ & & \\
\hline $\mathrm{PC}(\mathrm{kg})$ & 32,96 & 32,81 & $32,55 b$ & $33,22 \mathrm{a}$ & 0,0786 & 2,13 \\
\hline PCA (kg) & 31,58 & 31,58 & 31,30 & 31,86 & $0,0046^{*}$ & 1,98 \\
\hline PCV (kg) & 27,49 & 26,98 & $26,55 b$ & $27,93 \mathrm{a}$ & 0,1667 & 2,07 \\
\hline PCQ (kg) & 15,79 & 15,47 & $15,21 b$ & $16,05 a$ & 0,7274 & 3,14 \\
\hline $\mathrm{PCF}(\mathrm{kg})$ & 15,37 & 15,03 & $14,80 \mathrm{~b}$ & $15,61 \mathrm{a}$ & 0,7244 & 3,28 \\
\hline $\operatorname{PPR}(\%)$ & 2,66 & 2,80 & 2,70 & 2,76 & 0,8545 & 12,75 \\
\hline RCQ (\%) & 50,02 & 48,99 & $48,59 \mathrm{~b}$ & $50,42 \mathrm{a}$ & 0,1358 & 3,41 \\
\hline $\mathrm{RCF}(\%)$ & 48,69 & 47,62 & $47,28 b$ & 49,03 & 0,1431 & 3,45 \\
\hline RV (\%) & 57,43 & 57,32 & 57,28 & 57,48 & 0,4539 & 2,35 \\
\hline
\end{tabular}

Médias seguidas por letras distintas na linha diferem entre si pelo teste Tukey $(\mathrm{P}<0,05)$

*Significativo a $5 \%$ de probabilidade.

Gonzaga Neto et al. (2006) observaram que os rendimentos de carcaça quente e fria de cordeiros Morada Nova, alimentados com diferentes relações volumoso:concentrado e abatidos aos 17,21 e $25 \mathrm{~kg}$, foram maiores à medida que o teor de concentrado na dieta aumentou, com valores médios de 46,9 e $44,9 \%$, respectivamente. Esses valores foram mais baixos que os encontrados neste trabalho, podendo ser explicados provavelmente pelas diferenças entre as raças estudadas. Todos os rendimentos de carcaça quente e fria observados neste estudo foram superiores aos valores médios reportados por Parente et al. (2009), de 40,88\% e $39,66 \%$, respectivamente, que trabalharam com ovinos mestiços Santa Inês alimentados com diferentes dietas e abatidos aos $35 \mathrm{~kg}$ de peso corporal. Estas diferenças comprovam a eficiência da raça Ile de France como produtora de carne.

A perda de peso por resfriamento (PPR) consiste na perda de umidade da carcaça na câmara frigorífica e nas reações químicas do músculo durante o processo de resfriamento (Kirton, 1986). A porcentagem média de PPR dos tratamentos foi de $2,7 \%$, mais baixa que a reportada por Gonzaga Neto et al. (2006), de $5,00 \%$, que trabalharam com cordeiros Morada Nova. Este fato pode ser explicado pela maior 
cobertura de gordura na carcaça de cordeiros Ile de France em relação aos cordeiros Morada Nova, a qual protege a carcaça dos efeitos do frio e das perdas de peso durante o resfriamento. A maturidade do animal, a cobertura de gordura, as condições atmosféricas da câmara frigorífica e o tempo de armazenamento são fatores que interferem na porcentagem de perdas de peso ao resfriamento (Pinheiro, 2006).

Apesar de o tipo de volumoso ter influenciado $(\mathrm{P}<0,05)$ o peso do corpo vazio e o peso da carcaça quente, não foram encontradas diferenças $(\mathrm{P}>0,05)$ no rendimento verdadeiro, que consiste na relação entre peso de carcaça quente e peso do corpo vazio, com valor médio de 57,4\%. Siqueira e Fernandes (1999) relataram valores médios de $47,3 \%$ para rendimento verdadeiro da carcaça de cordeiros puros Corriedale e cruzados com Ile de France, alimentados com feno de coastcross e concentrado e abatidos aos $32 \mathrm{~kg}$ de peso corporal. Esse valor foi mais baixo que o encontrado no presente estudo.

$\mathrm{Na}$ Tab. 3, constam os pesos e as porcentagens dos cortes comerciais da carcaça, em que se observa que não houve efeito da interação $(\mathrm{P}<0,05)$ de relação volumoso:concentrado versus tipo de volumoso sobre os parâmetros avaliados.

Tabela 3. Peso $(\mathrm{kg})$ e rendimento $(\%)$ dos cortes comerciais da meia carcaça esquerda de cordeiros alimentados com silagem de milho ou cana-de-açúcar em dois níveis de concentrado

\begin{tabular}{|c|c|c|c|c|c|c|}
\hline \multirow[b]{2}{*}{ Variável } & \multicolumn{2}{|c|}{ Relação volumoso:concentrado } & \multicolumn{2}{|c|}{ Volumoso } & \multirow[b]{2}{*}{ Interação } & \multirow{2}{*}{$\begin{array}{l}\text { CV } \\
(\%)\end{array}$} \\
\hline & 40:60 & $60: 40$ & $\begin{array}{l}\text { Cana-de- } \\
\text { açúcar }\end{array}$ & $\begin{array}{l}\text { Silagem de } \\
\text { milho }\end{array}$ & & \\
\hline \multicolumn{7}{|l|}{ Paleta } \\
\hline $\mathrm{Kg}$ & 1,42 & 1,42 & 1,38 & 1,46 & 0,4725 & 6,83 \\
\hline$\%$ & 18,42 & 18,88 & 18,68 & 18,62 & 0,3987 & 7,15 \\
\hline \multicolumn{7}{|l|}{ Pescoço } \\
\hline $\mathrm{Kg}$ & 0,72 & 0,67 & 0,66 & 0,73 & 0,7024 & 11,56 \\
\hline$\%$ & 9,39 & 8,81 & 8,87 & 9,33 & 0,7660 & 11,20 \\
\hline \multicolumn{7}{|l|}{ Costela } \\
\hline $\mathrm{Kg}$ & 2,00 & 1,96 & 1,96 & 2,00 & 0,8847 & 6,13 \\
\hline$\%$ & 25,91 & 25,94 & 26,42 & 25,43 & 0,9568 & 5,02 \\
\hline \multicolumn{7}{|l|}{ Lombo } \\
\hline $\mathrm{Kg}$ & $0,76 \mathrm{a}$ & $0,69 b$ & $0,68 \mathrm{~b}$ & $0,77 \mathrm{a}$ & 0,0823 & 7,81 \\
\hline$\%$ & 9,79 & 9,17 & $9,11 \mathrm{~b}$ & $9,85 \mathrm{a}$ & 0,0725 & 7,42 \\
\hline \multicolumn{7}{|l|}{ Perna } \\
\hline $\mathrm{kg}$ & 2,80 & 2,77 & $2,72 b$ & $2,85 \mathrm{a}$ & 0,5684 & 4,27 \\
\hline$\%$ & 36,30 & 36,71 & 36,78 & 36,24 & 0,2161 & 2,84 \\
\hline
\end{tabular}

Médias seguidas por letras distintas na linha diferem entre si pelo teste Tukey $(\mathrm{P}<0,05)$

O peso do lombo foi afetado pela proporção e pelo tipo de volumoso da dieta, com maior peso para a relação $40: 60$, de $0,76 \mathrm{~kg}$, e quando se utilizou a silagem de milho como volumoso, de $0,77 \mathrm{~kg}$. O menor rendimento de lombo, 9,1\%, observado nos animais alimentados com canade-açúcar, pode ser atribuído aos menores pesos de carcaça quente e fria encontrados neste tratamento (Tab. 2), e por este ser o corte mais tardio da carcaça ovina.

Siqueira et al. (2001) estudaram as características quantitativas da carcaça de cordeiros e cordeiras $\mathrm{F}_{1}$ Ile de France $\mathrm{x}$ Texel, abatidos aos 28, 32, 36 e $40 \mathrm{~kg}$, e observaram que houve aumento linear das porcentagens dos cortes comerciais à medida que aumentou o peso de abate. Essa característica reforça a lei da harmonia anatômica de Boccard e Dumont (1960), que afirmam que, em carcaças de pesos e quantidades de gordura similares, quase todas as regiões corporais se encontram em proporções semelhantes, qualquer que seja a conformação dos genótipos considerados.

O tipo de volumoso também influenciou o peso da perna, com maior valor para os animais alimentados com silagem de milho, 2,85kg, entretanto não se observou diferença $(\mathrm{P}>0,05)$ quando a perna foi expressa em porcentagem do 
peso da meia carcaça, com valor médio de $36,5 \%$. A perna representa maior contribuição percentual na carcaça de ovinos, com maior rendimento da porção comestível e, além de predizer o conteúdo total dos tecidos, é o corte mais nobre da carcaça ovina (Sousa, 1993).

Oliveira et al. (2002) avaliaram o rendimento de cortes comerciais da carcaça de cordeiros Santa Inês e Bergamácia alimentados com dietas que continham dejetos de suínos e não observaram efeito da alimentação e da raça sobre os pesos e porcentagens de todos os cortes comerciais. Clementino et al. (2007) estudaram níveis crescentes de concentrado na dieta de cordeiros mestiços Dorper x Santa Inês e verificaram que houve efeito linear crescente nos pesos de todos os cortes comerciais da carcaça à medida que se elevaram os níveis de concentrado, entretanto não houve efeito sobre o rendimento do lombo com valor médio de $11,6 \%$, mais alto que o encontrado neste trabalho.

As porcentagens de paleta, 18,6\%, pescoço, $9,1 \%$, e perna, $36,5 \%$, foram similares às obtidas por Tonetto et al. (2004), ao trabalharem com cordeiros cruzados Texel x Ile de France, valores de $20,3 \% ; 8,0 \%$ e $34,6 \%$, respectivamente. Os distintos cortes que compõem a carcaça ovina possuem diferentes valores econômicos, e suas proporções constituem importante parâmetro para avaliação de sua qualidade comercial.

A composição dos tecidos, o índice de musculosidade e as relações músculo:osso e músculo:gordura obtidas pela dissecação da perna são apresentados na Tab. 4. Não houve diferença $(P>0,05)$ entre os tratamentos e nem efeito da interação da relação volumoso:concentrado versus tipo de volumoso sobre as características estudadas, exceto para porcentagem de gordura total. As porcentagens de músculo, 63,0\%, e osso total, $17,4 \%$ foram similares aos valores de $61,0 \%$ e $17,4 \%$, respectivamente, encontrados por Yamamoto (2006), ao avaliar dietas que continham silagens de resíduos de peixes na terminação de cordeiros 7/8 Ile de France/Ideal. Entretanto, esses autores reportaram maior porcentagem de gordura total, $20,7 \%$, em relação ao valor de $16,0 \%$ encontrado neste estudo, provavelmente devido ao maior teor de gordura nas dietas com silagem de resíduos de peixes.

Tabela 4. Composição tecidual e índice de musculosidade da perna de cordeiros alimentados com silagem de milho ou cana-de-açúcar em dois níveis de concentrado

\begin{tabular}{|c|c|c|c|c|c|c|}
\hline \multirow{2}{*}{ Variável } & \multicolumn{2}{|c|}{$\begin{array}{c}\text { Relação } \\
\text { volumoso:concentrado }\end{array}$} & \multicolumn{2}{|c|}{ Volumoso } & \multirow{2}{*}{$\begin{array}{c}\text { Interaçã } \\
\text { o }\end{array}$} & \multirow{2}{*}{$\begin{array}{l}\mathrm{CV} \\
(\%)\end{array}$} \\
\hline & $40: 60$ & $60: 40$ & $\begin{array}{l}\text { Cana-de- } \\
\text { açúcar }\end{array}$ & $\begin{array}{l}\text { Silagem } \\
\text { de milho }\end{array}$ & & \\
\hline Músculo total (\%) & 62,30 & 63,82 & 64,13 & 62,00 & 0,5156 & 5,22 \\
\hline \multicolumn{7}{|l|}{ Músculos da perna (g) } \\
\hline Biceps femoris & 215,04 & 219,70 & 213,21 & 221,54 & 0,4673 & 6,69 \\
\hline Semitendinosus & 97,74 & 99,56 & 95,47 & 101,82 & 0,2216 & 8,35 \\
\hline Adductor & 98,31 & 101,32 & 96,69 & 102,94 & 0,4638 & 9,47 \\
\hline Semimembranosus & 232,13 & 228,53 & 224,38 & 236,28 & 0,3289 & 7,35 \\
\hline Quadríceps femoris & 256,65 & 256,30 & 252,36 & 260,59 & 0,3190 & 11,08 \\
\hline Gordura total (\%) & 15,94 & 16,14 & 15,46 & 16,62 & $0,0434 *$ & 17,36 \\
\hline Subcutânea & 11,23 & 11,00 & 10,91 & 11,32 & 0,0562 & 19,41 \\
\hline Intermuscular & 4,71 & 5,13 & 4,54 & 5,30 & 0,1699 & 23,61 \\
\hline Osso total (\%) & 17,42 & 17,47 & 17,63 & 17,26 & 0,7540 & 6,51 \\
\hline Peso do fêmur (g) & 138,64 & 131,37 & 135,23 & 134,78 & 0,3766 & 5,97 \\
\hline $\mathrm{CF}(\mathrm{cm})$ & 15,83 & 15,81 & 15,86 & 15,78 & 0,3630 & 2,72 \\
\hline IMP & 0,47 & 0,48 & 0,47 & 0,48 & 0,1175 & 4,52 \\
\hline \multicolumn{7}{|l|}{ Relações } \\
\hline Músculo:osso & 3,58 & 3,68 & 3,65 & 3,60 & 0,4083 & 6,76 \\
\hline Músculo:gordura & 3,99 & 4,17 & 4,26 & 3,90 & 0,0988 & 21,07 \\
\hline
\end{tabular}

$\mathrm{CF}=$ comprimento do fêmur; IMP $=$ índice de musculosidade da perna.

Médias não diferiram pelo teste de Tukey $(\mathrm{P}>0,05)$.

*Significativo a $5 \%$ de probabilidade. 
Neste trabalho, o índice de musculosidade da perna foi de 0,47 , mais alto que $o$ valor encontrado por Marques et al. (2007), de 0,34, para cordeiros Santa Inês alimentados com diferentes níveis de inclusão de feno de flor-deseda na dieta. Essa superioridade pode ser atribuída à maior aptidão para produção de carne da raça Ile de France utilizada neste trabalho. Entretanto, foi semelhante ao valor de 0,49 reportado por Ribeiro et al. (2006), os quais trabalharam com cordeiros Suffolk terminados em confinamento e que receberam silagem de milho e concentrado ad libitum.

As relações músculo:osso e músculo:gordura não diferiram $(\mathrm{P}>0,05)$ entre os tratamentos. Os valores médios foram de 3,63 e 4,08, respectivamente, demonstrando que a silagem de milho e a cana-de-açúcar, ao constituir 40 ou $60 \%$ da dieta, não afetam a deposição dos tecidos ósseo, muscular e adiposo na perna de cordeiros. Segundo Santos et al. (2001), os músculos têm crescimento mais acelerado em animais mais jovens, e o teor de gordura é mais acentuado em animais adultos, sendo que os ossos apresentam menor velocidade de crescimento que os demais componentes da carcaça e dos cortes. Apesar da alta correlação com a composição tecidual da carcaça, a dissecação dos cortes comerciais tem a desvantagem de ser lenta e não poder ser utilizada na plataforma de abate comercial.

Silva Sobrinho et al. (2002) avaliaram o efeito da relação volumoso:concentrado e do peso de abate sobre os componentes da perna de cordeiros Ile de France x Ideal e relataram que houve menor relação músculo:osso e índice de musculosidade nos cordeiros alimentados com $70 \%$ de concentrado em relação aos alimentados com $50 \%$. Isso se explica pela maior deposição de gordura nos animais alimentados com maior teor de concentrado na dieta, entretanto o peso de abate não influenciou esses parâmetros. Os mesmos autores encontraram maior porcentagem de gordura intermuscular nos animais alimentados com maior teor de concentrado na dieta, $4,8 \%$, semelhante ao valor médio encontrado neste trabalho, 4,9\%. Segundo Osório (1992), a quantidade adequada de gordura influencia diretamente o valor comercial, enquanto o excesso resulta em depreciação da carcaça. Além disso, o excesso de gordura causa perdas de eficiência energética, o que aumenta o custo nutricional das dietas e causa prejuízos para a indústria frigorífica, pois há necessidade de mão de obra para retirar esse excesso de gordura, por meio do toalete dos cortes comercias.

\section{CONCLUSÕES}

Cordeiros alimentados com silagem de milho apresentaram maior rendimento de carcaça em relação aos alimentados com cana-de-açúcar, independentemente da relação volumoso: concentrado. A cana-de-açúcar em maiores quantidades na dieta propicia menor rendimento de lombo, indicando menor crescimento dos cordeiros, por ser o corte de desenvolvimento mais tardio da carcaça. A cana-de-açúcar e a silagem de milho nas duas relações volumoso:concentrado não afetam as proporções de osso, músculo e gordura da perna de cordeiros, e podem constituir a dieta desses animais, sem diminuir as proporções desses tecidos, responsáveis pela qualidade da carne de cordeiros.

\section{REFERÊNCIAS BIBLIOGRÁFICAS}

BOCCARD, R.; DUMONT, B.L. Etude de la production de la viande chez les ovins. II variation de l'importance relative des differents régions corporelles de l'agneau de boucherie. Ann. Zootech., v.9, p.355-365, 1960.

BROCHIER, M.A.; CARVALHO, S. Efeito de diferentes proporções de resíduo úmido de cervejaria sobre as características da carcaça de cordeiros terminados em confinamento. Arq. Bras. Med. Vet. Zootec., v.61, p.190-195, 2009.

BROWN, A.J.; WILLIANS, D.R. Sheep carcass evaluation: measurement of composition using a standardized butchery method. Langford: Agricultural Research Council, Meat Research Council, 1979. 16p. (Memorandum, 38).

BUTTERFIELD, R.M. New concepts of sheep growth. Sydney: University of Sydney, 1988. 168p.

CEZAR, M.F.; SOUSA, W.H. Carcaças ovinas e caprinas: obtenção, avaliação e classificação. Uberaba: Editora Agropecuária Tropical, 2007. $147 \mathrm{p}$.

CLEMENTINO, R.H.; SOUSA, W.H.; MEDEIROS, A.N. et al. Influência dos níveis de concentrado sobre os cortes comerciais, os constituintes não carcaça e os componentes da perna de cordeiros confinados. Rev. Bras. Zootec., v.36, p.681-688, 2007. 
GONZAGA NETO, S.; SILVA SOBRINHO, A.G.; ZEOLA, N.M.B.L. et al. Características quantitativas da carcaça de cordeiros deslanados Morada Nova em função da relação volumoso:concentrado na dieta. Rev. Bras. Zootec., v.35, p.1487-1495, 2006.

KIRTON, A.H. Animal industries workshop Lincoln College, technical handbook (lamb growth - carcass composition). 2.ed. Canterbury: Lincoln College, 1986. p.25-31.

MARQUES, A.V.M.S.; COSTA, R.G.; SILVA, A.M.A. et al. Rendimento, composição tecidual e musculosidade da carcaça de cordeiros Santa Inês alimentados com diferentes níveis de feno de florde-seda na dieta. Rev. Bras. Zootec., v.36, p.610$617,2007$.

McCUTCHEON, S.N.; BLAIR, H.T.; PURCHAS, R.W. Body composion and organ weights in fleeceweight selected and control Romney rams. $N$. Z. J. Agric. Res., v.36, p.445-449, 1993.

NUTRIENT requirements of sheep. Washington: National Academy of Sciences, 1985. 99p.

OLIVEIRA, N.M.; OSÓRIO, J.C.S.; MONTEIRO, E.M. et al. Produção de carne em ovinos de cinco genótipos. 4. Composição regional e tecidual. Cienc. Rural, v.28, p.125-129, 1998.

OLIVEIRA, M.V.M.; PÉREZ, J.R.O.; ALVES, E.L. et al. Rendimento de carcaça, mensurações e peso de cortes comerciais de cordeiros Santa Inês e Bergamácia alimentados com dejetos de suínos em confinamento. Rev. Bras. Zootec., v.31, supl.3, p.1451-1458, 2002.

OSÓRIO, J.C.S. Estúdio de la calidad de canales comercializadas em el tipo ternasco seun la procedencia: bases para la mejora de dicha em Brasil. 1992. 335f. Tese (Doutorado) - Universidad de Zaragoza, Zaragoza.

PARENTE, H.N.; MACHADO, T.M.M.; CARVALHO, F.C. et al. Desempenho produtivo de ovinos em confinamento alimentados com diferentes dietas. Arq. Bras. Med. Vet. Zootec., v.61, p.460-466, 2009.

PINHEIRO, R.S.B. Aspectos quantitativos da carcaça e qualitativos da carne de ovinos de diferentes categorias. 2006. 115f. Dissertação (Mestrado) - Faculdade de Ciências Agrárias e Veterinárias, Universidade Estadual Paulista, Jaboticabal.
PURCHAS, R.W.; DAVIES, A.S.; ABDULLAH, A.Y. An objective measure of muscularity: changes with animal growth and differences between genetic lives of Southdown sheep. Meat Sci., v.30, p.81-94, 1991.

RIBEIRO, T.M.D.; MONTEIRO, A.L.G.; POLI, C.H.E.C. et al. Composição tecidual do lombo e da perna de cordeiros terminados em diferentes sistemas de criação. In: REUNIÃO ANUAL DA SOCIEDADE BRASILEIRA DE ZOOTECNIA, 43., 2006, João Pessoa. Anais... João Pessoa: SBZ, 2006. (CD-ROM).

SANTOS, C.L. Sistemas de cortes de cordeiros. In: SIMPÓSIO MINEIRO DE OVINOCULTURA, 2., 2002, Lavras. Anais... Lavras: UFLA, 2002. p.187206.

SANTOS, C.L.; PÉREZ, J.R.O. Cortes comerciais de cordeiros Santa Inês. In: ENCONTRO MINEIRO DE OVINOCULTURA, 1., 2000, Lavras. Anais... Lavras: UFLA, 2000, p.150-168.

SANTOS, C.L.; PÉREZ, J.R.O.; MUNIZ, J.A. et al. Desenvolvimento relativo dos tecidos ósseo, muscular e adiposo dos cortes da carcaça de cordeiros Santa Inês. Rev. Bras. Zootec., v.30, p.487-492, 2001.

SAÑUDO, C.; SIERRA, I. Calidad de la canal en la especie ovina. Ovino, v.11, p.127-153. 1986.

SILVA, L.F.; PIRES, C.C. Avaliações quantitativas das proporções de osso, músculo e gordura da carcaça em ovinos. Rev. Bras. Zootec., v.29, p.1253-1260, 2000.

SILVA SOBRINHO, A.G. Body composition and characteristics of carcass from lambs of different genotypes and ages at slaughter. 1999. 54f. Thesis (PostDoctorate) - Massey University, Palmerston North.

SILVA SOBRINHO, A.G. Criação de ovinos, 2. Jaboticabal: FUNEP, 2001. 302p.

SILVA SOBRINHO, A.G.; MACHADO, M.R.F.; GASTALDI, K.A. et al. Efeitos da relação volumoso:concentrado e do peso ao abate sobre os componentes da perna de cordeiros Ile de France $\mathrm{x}$ Ideal confinados. Rev. Bras. Zootec., v.31, supl.2, p.1017-1023, 2002.

SIQUEIRA, E.R.; FERNANDES, S. Pesos, rendimentos e perdas da carcaça de cordeiros Corriedale e mestiços Ile de france x Corriedale, terminados em confinamento. Cien. Rural, v.29, p.143-148, 1999. 
SIQUEIRA, E.R.; SIMÕES, C.D.; FERNANDES, S. Efeito do sexo e do peso ao abate sobre a produção de carne de cordeiro: morfometria da carcaça, pesos dos cortes, composição tecidual e componentes não constituintes da carcaça. Rev. Bras. Zootec., v.30, p.1299-1307, 2001.

SOUSA, O.C.R. Rendimento de carcaça, composição regional e física da paleta e quarto em cordeiros Romney Marsh abatidos aos 90 e 180 dias de idade. 1993. 120f. Dissertação (Mestrado) Universidade Federal de Pelotas, Pelotas.

TONETTO, C.J.; PIRES, C.C.; MÜLLER, L. et al. Características da carcaça de cordeiros terminados em dieta isoproteica contendo forragem hidropônica de milho ou capim-elefante. In: REUNIÃO ANUAL DA SOCIEDADE BRASILEIRA DE ZOOTECNIA, 41., 2004, Campo Grande. Anais... Campo Grande: SBZ, 2004. (CD-ROM).
YAMAMOTO, S.M. Desempenho e características da carcaça e da carne de cordeiros terminados em confinamento com dietas contendo silagens de resíduos de peixes. 2006. 106f. Tese (Doutorado) Faculdade de Ciências Agrárias e Veterinárias, Universidade Estadual Paulista, Jaboticabal.

ZUNDT, M.; MACEDO, F.A.F.; MARTINS, E.N. et al. Características de carcaça de cordeiros terminados em confinamento, com dietas contendo diferentes níveis proteicos. Cienc. Rural, v.33, p.565-571, 2003. 